\title{
연안도시 지역의 방재성능목표 설정 및 개선방안 고찰 An Analytical Study of the Problems and a Plan for Improving of Disaster Prevention Performance in Coastal Cities
}

\author{
최경민* - 이정호** . 함대헌*** . 박윤경**** . 송양호***** \\ Choi, Gyungmin*, Lee, Jungho**, Ham, Daeheon**, Park, Yoonkyung ${ }^{* * * *}$, and Song, Yang Ho****
}

\begin{abstract}
The phenomenon and impact of abnormal weather caused by climate change is not limited domestically, and the frequency and magnitude of natural disasters are increasing. In Korea, heavy rainfall has occurred, and sea level rise is accelerating. This falls under domestic urban disasters, which cause severe damage due to multiple floods in the coastal cities. In this study, the risk of disaster in the coastal cities was examined using XP-SWMM. In order to tackle the risk of flooding due to sea level rise, we examined whether the performance targets for the prevention of disasters were appropriate. Performance targets for the prevention of disasters and various scenarios of sea level rise were applied to the urban drainage system in Changwon City, where flood damage had occurred due to sea level rise. In spite of the freefall conditions for the currently set performance targets for the prevention of disasters, it was confirmed that there is a greater risk of flooding due to sea level rise. The results of this study show the spatial variation of flood risk due to sea level change near the coastal cities. Furthermore, these results can be used as reference data for establishing countermeasures to tackle related disasters.
\end{abstract}

Key words : Climate Change, Heavy Rainfall, Coastal City, Urban Sewer, XP-SWMM

\section{요 지}

기후변화로 인한 이상기후 현상은 비단 국내에 국한되지 않고 전 세계적으로 나타나고 있으며 이로 인한 자연재해의 발생빈도와 크기가 증가하고 있다. 국내에서는 집중호우와 해수면 수위의 상승이 가속화 되어 기존의 도심지 내수재해 발생 유형과 맞물려 연안도시 지역에 복합적인 침수피해를 초래하고 있다. 본 연구에서는 XP-SWMM 모형을 이용하여 연안도시 지역의 재해발생 위험성을 고찰하고 해수면 상승에 따른 침수위험을 사전에 대비하기 위한 방재성능목표의 적정성을 검토하였다. 해수면 상승에 따른 침수피해가 발생했던 창원시 일대 우수관망을 대상으로 방재성능목표와 해수면 상승시나리오를 적용하였다. 현재 설정된 방재성능목표에 대한 자연유출 조건에서도 일부 침수에 노출되어 있음을 확인하였으며 해수위 상승에 따른 침수위험도가 증가하는 것을 확인하였다. 본 연구를 통해 제시한 결과들은 연안도시 인근의 해수면 변화에 따른 침수위험도를 시공간적인 변화 양상으로 살펴볼 수 있으며 나아가 관련 치수대책 수립시 참고자료로 활용이 가능하다.

핵심용어 : 기후변화, 집중호우, 연안도시, 우수관거, XP-SWMM

*정회원, 국립한밭대학교 건설환경공학과 석사과정(E-mail: withckm@gmail.com)

Member, Master Course Student, Department of Civil \& Environmental Engineering, Hanbat National University

**정회원, 국립한밭대학교 건설환경공학과 교수(E-mail: leejh@hanbat.ac.kr)

Member, Professor, Department of Civil \& Environmental Engineering, Hanbat National University

***정회원, 서울과학기술대학교 건설기술연구소 선임연구원(E-mail: daeheon80@naver.com)

Member, Senior Researcher, Institute of Construction Technology, Seoul National University of Science and Technology

****정회원, 한국건설기술연구원 국토보전연구본부 도시물순환연구센터 박사후연구원(E-mail: parkyoonkyung@kict.re.kr)

Member, Postdoctoral Fellow, Department of Land, Water \& Environment Research Urban Water Cycle Research Center, Korea Institute of

Civil Engineering and Building Technology (KICT)

*****교신저자, 정회원, 국립한밭대학교 건설환경공학과 연구교수(E-mail: syho@daum.net)

Corresponding Author, Member, Research Professor, Department of Civil \& Environmental Engineering, Hanbat National University 


\section{1. 서 론}

전 지구적인 기후변화의 영향으로 빙하감소, 가뭄 - 사막 화 등 기후에 민감한 환경 - 생태계의 변화가 가속화 되고 있다(UN, 2014). 기후변화에 따른 수자원의 극단적인 변화 는 이미 전 세계에 걸쳐 관찰되었다(IPCC, 2014). 관련 연구 동향을 살펴보면 증발산량의 변화에 따른 강우-유출의 비선 형성 문제, 지역별 강우의 초과발생빈도와 양적 증가 및 이에 따른 하천홍수량 증가에 따른 범람 우려에 대한 연구가 활발히 진행되고 있으며 최근에는 시설물들의 설계연한을 상회하는 강우 발생에 따른 첨두유출량의 증가로 홍수발생 의 위험성을 사전에 인식하고 대비책을 수립해야 한다는 의견들이 제시되고 있다(Cifrodelli et al., 2015; Akter et al., 2018; Fadhel et al., 2018; Chu et al., 2019; Verstraten et al., 2019).

더불어 기후변화의 영향으로 인한 극한 호우사상의 발생 과 해수면 상승의 문제는 해안가에 위치한 도시지역의 홍수 위험도 증가에 직접적으로 기인한다. 많은 인구가 거주하는 연안지역의 미래 해수면 상승에 대한 전망을 국가 정책에 반드시 반영해야 한다(Cha et al., 2016; Park et al., 2018). 육지와 해양의 경계부인 연안은 가장 심각하게 영향을 미칠 것으로 판단된다. 특성상 인구 및 산업 시설이 집중되어 있어 사회경제적으로 수송, 산업시설, 자원, 관광 등 인간과 밀접한 관계가 있는 곳이기 때문이다. 그러므로 미래에 해수 면이 어느 정도까지 상승할 것인가에 대한 예측은 연안재해 대응을 위한 시작점이라 할 수 있다(Joo, 2015). 해수면 상승 은 자연생태계 및 사회경제적으로 주요한 연안에 다양한 영향을 주며 그 결과 수자원을 포함한 사회전반의 인프라에 악영향을 미칠 것으로 예상된다. 연안의 경우 기후변화로 인한 강수 및 태풍의 강도와 빈도 변화에도 영향을 받기 때문에 기후변화에 취약한 지대로 인식되고 있다(Cho and Maeng, 2007; Kim et al., 2019). 저지대에 위치한 해안가 지역의 경우 해수위 상승과 더불어 집중호우 두 가지의 문제점을 함께 고려하여 침수발생의 위험에 대비해야 한다 (Jones et al., 2013; Roberts et al., 2017). 결과적으로 연안도시 지역의 특성을 고려한 강우-유출 분석을 수행하고 이를 바탕으로 지역별 방재성능목표 강우량(Disaster Prevention Performance Target Rainfall)을 설정하고 지역별 치수계획을 수립해야 할 필요성이 있다.

최근 기후변화의 영향을 고려한 도시지역의 방재성능목 표를 평가하고 대응방안을 마련하는 연구가 진행되고 있으 며 해수면 상승을 고려한 연안지역의 침수위험 평가와 관련 된 연구들도 진행되고 있다. Hong et al. (2013)은 부산 영도 일대를 대상으로 $\mathrm{CAD}$ 를 이용한 해수면 상승 시뮬레이 션을 실시하였으며 과를 바탕으로 침수범위와 재해위험지 역을 종합적으로 고려하여 피해 예상지역을 제시하는 방법 론을 제안하였다. Ahn (2014)은 기수립된 방재성능목표
강우량의 강우지속기간의 적정성을 판단하고자 강우-유출 모형을 이용하여 강우지속기간과 임계지속기간의 최대유 출량을 비교하였다. Kim (2016)은 도시방재성능 목표를 적용하여 침수원인 분석을 수행하였으며 관거의 개량 및 유역 특성을 고려한 방수로 신설 등의 저감대책의 필요성을 제안하였다. Lee et al. (2016)은 도시의 내수침수 문제는 내륙도시보다 하천이나 바다에 인접한 연안도시에서 더 큰 피해가 발생하고 있음을 주장하였으며 해수면 상승에 따른 치수능력의 저하의 문제를 고려하고 방재성능목표 강우량 설정에 대한 연계분석을 제안하였다. Jeong et al. (2017)은 기존 방재성능목표 강우량 산정 기준에 있어 도시 지역별 특성을 고려한 가중치 적용의 필요성을 제안하였으 며 이를 고려한 목표 강우량을 산정하고 기존 자료들과의 비교·검토를 수행하였다. Ko et al. (2018)은 방재성능목표 강우량을 설정하는 방법에 있어 산악지역 및 섬에 의한 강우 특성은 반영하지 못하고 있음을 지적하며 지역적 특성 을 고려한 강우 분석을 수행하였다. Park et al. (2018)은 방재성능목표를 설정함에 있어 강우의 크기 변화만을 다루 고 있는 면과 달리 복합원인으로 발생하는 연안도시의 지역 적 특성을 반영해야 함을 제안하였으며 지속시간별 침수발 생의 확장성을 검토하였다.

선행 연구들은 기후변화를 고려한 지역별 재해발생 위험 성을 고찰하고 사전에 대비하기 위한 지역적 특성별 방재성 능목표를 검토하였다. 다만 지역의 기후특성, 미래여건 변화 등을 고려하고 면(面)적 개념의 공간 단위에서 분담할 수 있는 목표강우량 설정이라는 취지에 부합하기 위해서는 내륙에 위치한 도시지역과 더불어 하천이나 해수위 영향에 직접적인 영향을 받는 연안지역에 대한 다양한 결과들이 도출되어야만 한다.

본 연구에서는 육지와 해양의 경계부에 위치한 연안도시 지역이 가장 심각한 영향권역이라 판단하고 해수면 상승의 위험을 부담한 조건에서 설정된 목표강우량의 적절성을 검토하고자 한다. 기 설정된 방재성능목표 강우량과 해수면 상승의 조합을 토대로 연안도시 지역에 미치는 영향을 검토 하고 보완이 필요한 부분에 대한 당위성을 제시하고자 한다. 먼저, 해수면 상승에 따른 실제 침수피해를 겪은 연안도시를 조사하고 대표 지역을 선정하여 강우-유출 모델을 구축하였 다. 다음은 해당 지역에 수립된 방재성능목표와 향후 발생가 능한 해수면 상승시나리오를 구성하고 이들을 조합한 침수 해석을 수행하였다.

\section{2. 연구방법}

도시지역의 우수관망을 고려한 내수모의와 하천을 고려 한 외수모의의 경우 강우-유출해석 모델을 구축하여 강우-유 량-수위 관계를 도출하는 것이 일반적이다. 연안도시 지역의 경우 해수면 상승시 침수에 노출된 범위가 광범위하게 발달 
하기 때문에 기존의 방법론을 동일하게 적용하는 경우 도출 된 결과의 신뢰도가 낮을 것으로 판단된다. 해수위 상승에 따른 침수발달의 범위를 구분하여 살펴보고 현재 고려하고 자 하는 방재성능목표에 대한 의미를 살펴보아야 한다. 본 연구에서는 해안가에 위치한 주요 연안지역을 대상으로 해수위 상승을 고려한 해석 모델을 구축하고 모의된 결과들 을 침수예상도로 도출함으로써 해수위 변화에 대한 기수립 된 방재성능목표의 적정성을 검토하고자 한다.

\section{1 적용대상 유역 검토 및 강우-유출해석 모델 구축}

본 연구에서는 과거 해수위 상승시 재해가 발생했던 도시 지역을 검토하였으며 이들 중 창원시에 위치한 창원시 마산 회원구에 위치한 마산자유무역지역 일대를 적용대상 유역 으로 선정하였다(Fig. 1). 해당 지역은 남해의 조위의 직접적 인 영향을 받는 지역을 선정하였다. 적용대상 유역은 국가산 업단지의 특성상 대규모 산업시설이 밀집되어 있으며 인구 유동 및 물류·배송을 위한 유동차량이 많은 특성을 갖는다. 산업단지 내 침수발생시 산업시설 및 토지의 피해에 따른 경제적 피해에 그치지 않고 환경 및 안전사고와 같은 2차 피해로 확산될 우려가 있다. 이처럼 기후변화를 고려하지 못하고 현행 기준으로 산업단지의 배수시설 계획을 수립 유지할 경우, 연안도시 지역에 위치한 산업단지는 해수면 상승 및 폭풍해일고 증가와 더불어 집중호우 발생시 침수, 범람이 불가피할 것이다.

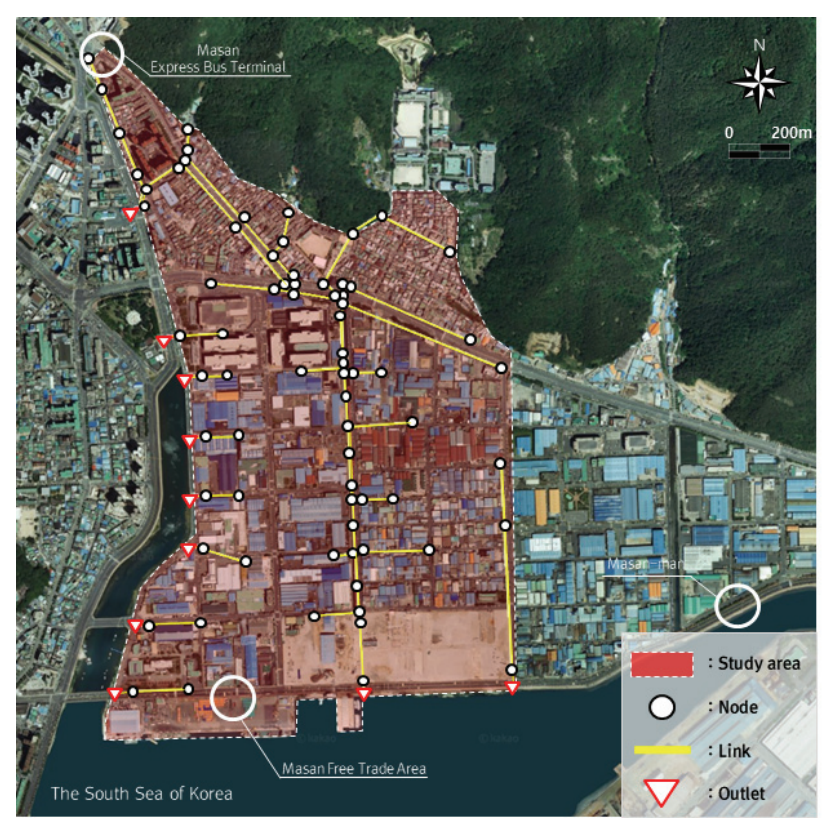

Fig. 1. Watershed and Sewer Network of Study Area

적용대상 유역은 남해의 직접적인 조위영향 구간에 속 하며 해수면 상승시 침수발생의 위험에 노출되어 있는
지역으로 지난 2016년 10월 5일 태풍 ‘차바' 내습 당시와 2018년 8월 12일에 해안가 일대의 침수가 발생한 사례가 있다. 더욱이 강우가 발생하지 않은 상황에서도 단지 해수 면 상승에 따른 침수피해가 발생하고 있는 상황에서 홍수 재해를 예방하기 대비책이 강구되어야 한다. 분석을 위해 창원시 마산회원구 양덕 - 봉암동에 걸쳐 약 $232 \mathrm{ha}$ 에 대해 XP-SWMM 모형을 이용하여 강우-유출해석 모델을 수립 하였다. 보다 자세한 적용유역의 특성은 Table 1 을 통해 확인할 수 있다.

Table 1. Watershed Properties of Study Area

\begin{tabular}{c|c}
\hline Category & Specification \\
\hline Address & $\begin{array}{c}\text { Yangdeok/Bongam-dong, } \\
\text { Masanhoewon-gu, Changwon-si, } \\
\text { Gyeongsangnam-do, Korea }\end{array}$ \\
\hline Area & 232 ha \\
\hline Number of nodes/links & $85 / 76 \mathrm{EA}$ \\
\hline Number of outlets & $10 \mathrm{EA}$ \\
\hline Watershed direction & The Southern Sea of Koea \\
\hline
\end{tabular}

\section{2 해수면 상승 및 방재성능목표 강우량을 고려한 분석 시나리오 수립}

행정안전부에서는 '미래 기후변화 영향을 고려한 지역별 방재성능목표 설정 · 운영 기준(MOIS, 2017)’을 통해 지역 별 방재성능목표를 제시하였다. 해당 목표는 기후변화와 도시화로 인해 심화되는 도시지역의 침수피해를 예방하기 위해 지자체별로 정한 시간당 처리 가능한 강우량의 크기를 의미하며, 각 지자체는 목표에 맞춰 배수시스템을 개선해야 한다고 규정하고 있다. 그러나 현행 방재성능목표 강우량의 경우 기후변화에 따른 해수위 상승에 대한 위험성을 고려하 고 있지 않다. 연안도시와 같은 지역적 특성이 일반 내륙지역 과 상이한 경우에는 방재성능목표의 본래의 취지에 부합하 도록 강우량 설정에 있어 해수위 상승에 대한 관계가 고려되 어야만 한다.

본 연구에서는 창원시의 방재성능목표 강우량과 Park et al. (2018)이 도출한 창원시 일대의 빈도별 해수면 상승 및 폭풍해일고를 조합한 시나리오를 설정하고 분석을 수행하 였다. Fig. 2는 창원시 일대의 방재성능목표 강우량을 가리킨 다. 해당 강우량을 바탕으로 Huff 3 분위법(Huff's Quartile Method)을 적용하여 시간적 분포를 고려하였다. Fig. 3은 창원시 일대 해안가의 해수면 상승을 고려한 약최고고조위 (Approximately Highest High Water Level, A.H.H.W.L)와 빈도별 폭풍해일고이며 해당 자료를 바탕으로 분석을 위한 외수위 조건으로 적용하였다(Table 2). Zone A C의 경우 분석대상 지역 내 10 개의 방류구의 위치별로 구분·적용한 해수위 경계조건을 나열하였다(Table 3). 
Table 2. Probable Rainfall of 30 -year Frequency in Changwon

\begin{tabular}{c|c}
\hline Duration & Probable Rainfall $(\mathrm{mm})$ \\
\hline $1-\mathrm{hr}$ & 88.3 \\
\hline $2-\mathrm{hr}$ & 131.0 \\
\hline $3-\mathrm{hr}$ & 153.5 \\
\hline
\end{tabular}

Table 3. The Rising Sea Level of Changwon Coast (Park et al., 2018)

\begin{tabular}{c|c|c|c|c|c|c}
\hline \multicolumn{2}{c|}{ Area } & A.H.H.W.L & $\begin{array}{c}10 \text {-yr frequency } \\
\text { storm }\end{array}$ & $\begin{array}{c}30 \text {-yr frequency } \\
\text { storm }\end{array}$ & $\begin{array}{c}50 \text {-yr frequency } \\
\text { storm }\end{array}$ & $\begin{array}{c}100 \text {-yr frequency } \\
\text { storm }\end{array}$ \\
\hline \multirow{2}{*}{$\begin{array}{c}\text { Yangdeok } \begin{array}{c}\text { storict } \\
\text { district }\end{array} \\
\text { Zongam }\end{array}$} & Zone A & 0.98 & 2.26 & 2.87 & 3.19 & 3.63 \\
\cline { 2 - 8 } & Zone B & 0.98 & 2.23 & 2.84 & 3.14 & 3.58 \\
\cline { 2 - 8 } & Zone C & 0.98 & 2.23 & 2.84 & 3.15 & 3.58 \\
\hline
\end{tabular}

\section{3. 연구결과}

대상 유역에서의 분석을 위한 XP-SWMM 모형 구축시 수리계산서를 바탕으로 초기 모형을 구축하고 빈도별 설계 강우를 적용하여 관로유출 및 수위변동성을 모의하였다. 이 과정에서 모형 매개변수의 보정을 통하여 개별 관거에 명시된 유출량 값의 검증과정을 거쳐 모델을 완성하였다.

기존의 설계빈도 토대로 자연방류 조건을 고려한 경우 연구대상 지역에 홍수는 발생하지 않았다. 따라서 강우량 자료만 사용하여 연안도시 지역의 방재성능목표를 결정하 고 홍수위험도를 산출하는 것은 과소평가 될 가능성이 존재 한다. 유역 내 전체 방류토구가 해안가로 향하여 조위의 직접적인 영향을 받을 것으로 사료된다. 실제 해수위 증가에
따른 배수위 조건을 반영된 결과 자연방류 조건과 달리 침수의 발생 및 확장이 두드러지게 나타났다. 결과들을 Tables 4 6과 Figs. 2 4에 나열하였다.

Tables 4 6은 방재성능목표 강우의 지속시간별 해수위 상승조건에 대한 분석결과이다. 먼저 Table 4 의 1 시간에 대한 결과를 살펴보면 자연방류 조건에서도 5 개의 절점에서 약 $10 \mathrm{ha}$ 의 침수면적이 발생하였음을 확인할 수 있다. Tables 5,6 의 자연방류 조건에서도 동일하게 침수가 발생하는 것을 확인할 수 있고 해안가에 위치한 간선관거를 제외한 상류의 일부 지선관거에서 침수가 발생하는 결과를 비추어볼 때 연구대상 지역은 설계 강우사상에 대한 적정 통수능을 확보 하고는 있지만 방재성능목표에 대해서는 충족하지 못하는 것으로 사료된다.

Table 4. Comparison of Overflow Results for Sea Level Conditions (Duration 1-hr)

\begin{tabular}{|c|c|c|c|c|c|c|}
\hline \multirow{3}{*}{ Results } & \multicolumn{6}{|c|}{ Duration } \\
\hline & \multicolumn{6}{|c|}{$1-\mathrm{hr}$} \\
\hline & Freefall & A.H.H.W.L & $10-y r$ & $30-y r$ & $50-\mathrm{yr}$ & $100-\mathrm{yr}$ \\
\hline Number of flooding node (EA) & 5 & 19 & 20 & 20 & 20 & 20 \\
\hline Overflow volume $\left(\mathrm{m}^{3}\right)$ & 24,564 & 31,787 & 65,386 & 208,979 & 224,076 & 225,462 \\
\hline Flooding area (ha) & 10.219 & 12.354 & 20.062 & 42.592 & 44.008 & 45.399 \\
\hline Maximum flooding depth (m) & 2.58 & 2.58 & 2.90 & 2.95 & 2.95 & 2.95 \\
\hline
\end{tabular}

Table 5. Comparison of Overflow Results for Sea Level Conditions (Duration 2-hr)

\begin{tabular}{|c|c|c|c|c|c|c|}
\hline \multirow{3}{*}{ Results } & \multicolumn{6}{|c|}{ Duration } \\
\hline & \multicolumn{6}{|c|}{ 2-hr } \\
\hline & Freefall & A.H.H.W.L & $10-y r$ & $30-y r$ & $50-\mathrm{yr}$ & $100-y r$ \\
\hline Number of flooding node (EA) & 4 & 19 & 20 & 22 & 23 & 23 \\
\hline Overflow volume $\left(\mathrm{m}^{3}\right)$ & 32,699 & 39,711 & 76,860 & 236,969 & 257,966 & 260,315 \\
\hline Flooding area (ha) & 10.007 & 12.233 & 22.167 & 47.674 & 49.441 & 49.441 \\
\hline Maximum flooding depth (m) & 4.08 & 4.10 & 4.61 & 4.67 & 4.67 & 4.67 \\
\hline
\end{tabular}


Table 6. Comparison of Overflow Results for Sea Level Conditions (Duration 3-hr)

\begin{tabular}{c|r|r|r|r|r|r}
\hline \multirow{2}{*}{ Results } & \multicolumn{5}{|c}{ Duration } \\
\cline { 2 - 7 } & \multicolumn{5}{|c}{3 -hr } \\
\cline { 2 - 7 } & \multicolumn{1}{c}{ Freefall } & A.H.H.W.L & 10 -yr & 30 -yr & 50 -yr & 100 -yr \\
\hline Number of flooding node (EA) & 4 & 19 & 20 & 23 & 23 \\
\hline Overflow volume (m $\left.{ }^{3}\right)$ & 32,713 & 39,680 & 79,244 & 248,456 & 276,059 & 279,488 \\
\hline Flooding area (ha) & 9.039 & 11.435 & 22.058 & 49.416 & 51.510 & 51.510 \\
\hline Maximum flooding depth (m) & 4.21 & 4.22 & 4.80 & 4.88 & 4.88 & 4.88 \\
\hline
\end{tabular}

해수면이 약최고고조위부터 10 년빈도 폭풍해일고까지 약 0.98 $2.87 \mathrm{~m}$ 가 상승하는 조건에 대한 결과들을 살펴보면 기존 자연방류 조건에서 발생했던 최대침수심은 대체적으 로 유사한 결과로 나타났다. 그러나 침수면적과 월류발생량 이 크게 증가하는 경향이 나타났다. 결과의 경향성은 2 , 3시간의 조건에 대해서도 동일하게 나타났다. 지난 2016년 10 월 18 일 당시의 창원시 해수위와 유사한 약 30 년빈도 이상의 폭풍해일고의 경우 지속시간에 관계없이 침수발생 결과가 급격하게 증가하는 것을 확인할 수 있었다. 이러한 결과는 해수면과 강우량의 관계없이 해수면 상승에 따른 분석대상 지역의 침수위험도에 노출되어 있음을 가리킨다. Lee et al. (2016)은 이러한 현상을 고려하여 연안도시 지역에
대한 방재성능목표 강우량이 약 $30 \%$ 정도 낮아져야 함을 제안하였다. 그러나 본 연구에서의 결과들을 비추어 볼 때 Lee et al. (2016)이 제안한 내용 이상의 목표치에 대한 검토과 정을 통해 연안도시 지역들에 대한 근본적인 침수위험성을 저감방안이 마련되어야 한다.

본 연구에서는 기 설정된 방재성능목표 강우량이 연안도 시 지역의 해수위 상승을 고려하였을 때 실제 적절한지 판단하기 위한 개략적인 분석을 수행하였다. 도출된 결과는 미흡한 목표설정에 따른 실제 유역이 갖는 재해위험성이 매우 크다는 것을 의식하게 할 수 있으며 보다 효과적인 관리목표를 설정할 필요가 있다. Tables 4 6에 대한 모의 결과를 다음의 Figs. 2 4에 나타내었다.

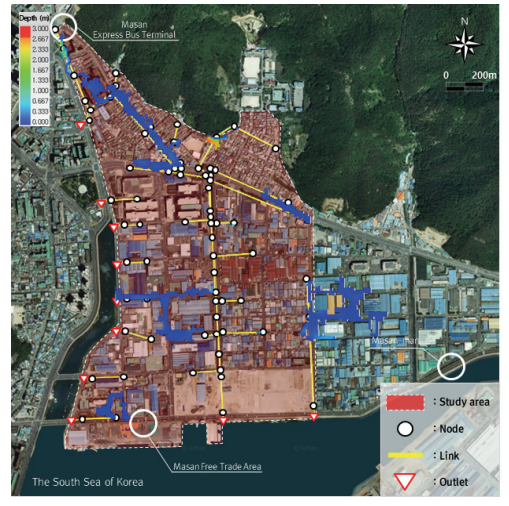

(a) Freefall condition

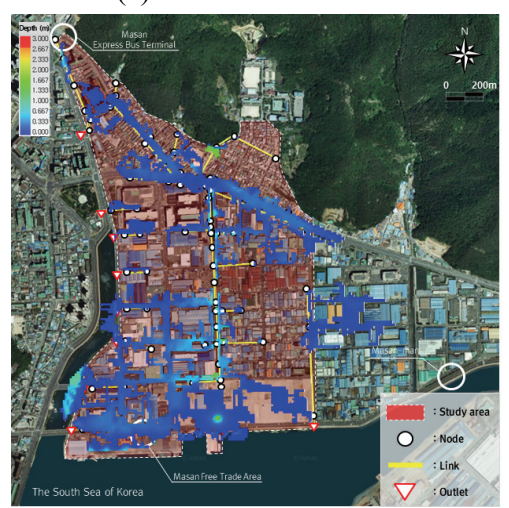

(d) 30-yr frequency condition

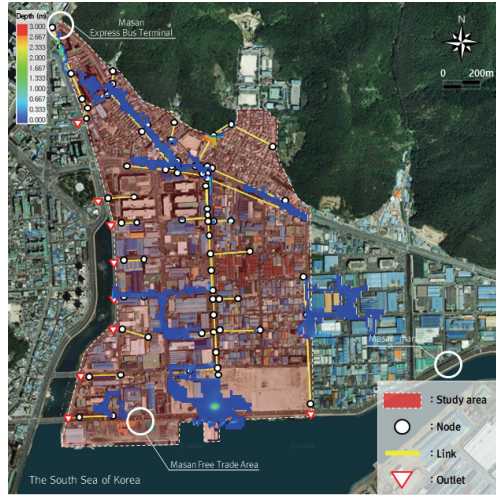

(b) A.H.H.W.L condition

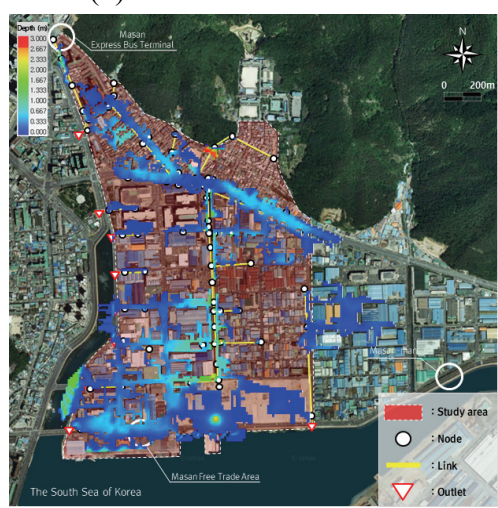

(e) 50-yr frequency condition

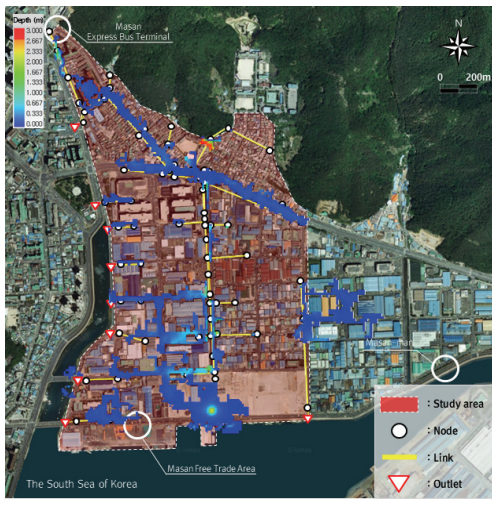

(c) $10-y r$ frequency condition

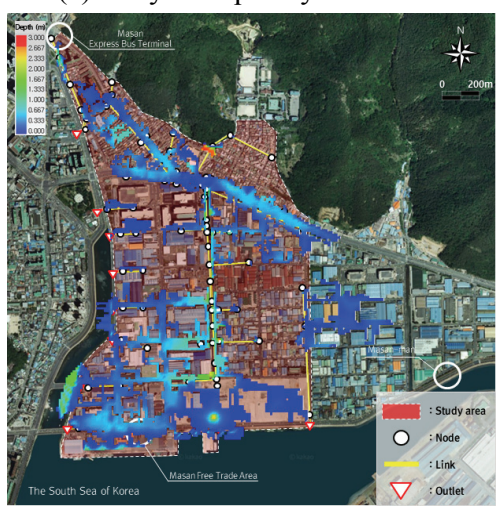

(f) 100-yr frequency condition

Fig. 2. Comparison of Flooding Results for Sea Level Conditions (Duration 1-hr) 


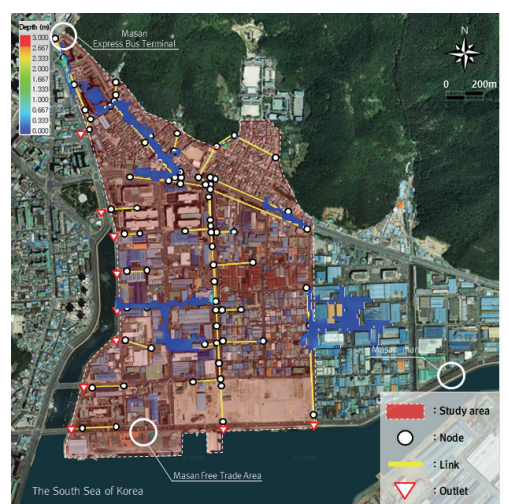

(a) Freefall condition

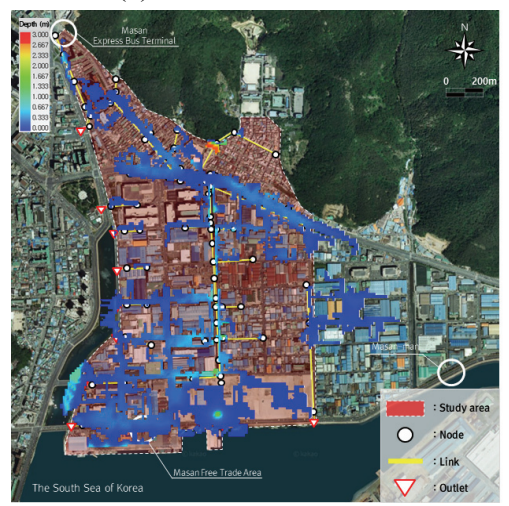

(d) 30-yr frequency condition

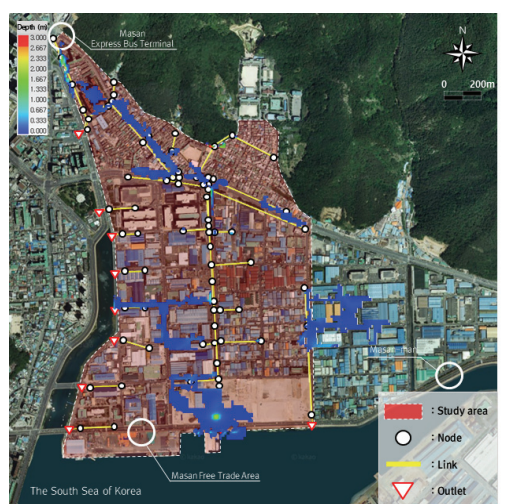

(b) A.H.H.W.L condition

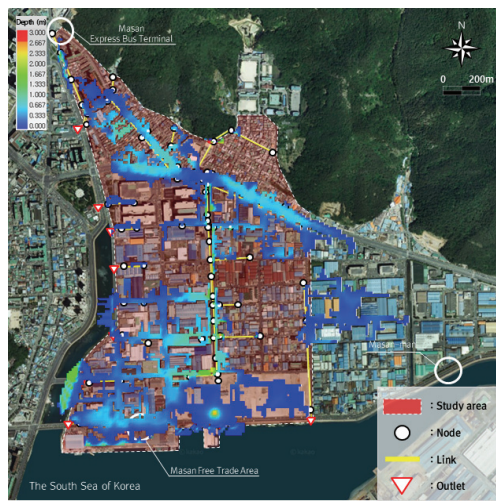

(e) 50-yr frequency condition

Fig. 3. Comparison of Flooding Results for Sea Level Conditions (Duration 2-hr)

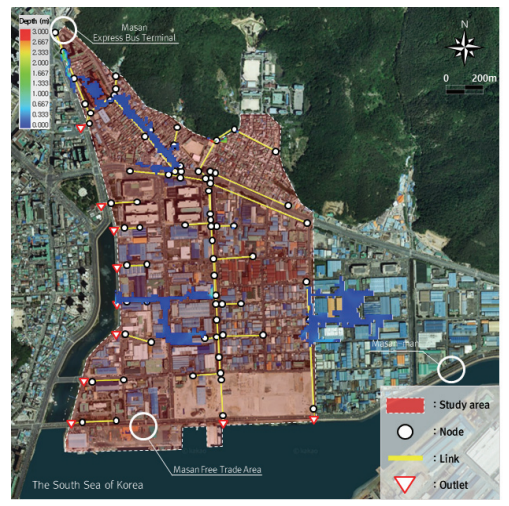

(a) Freefall condition

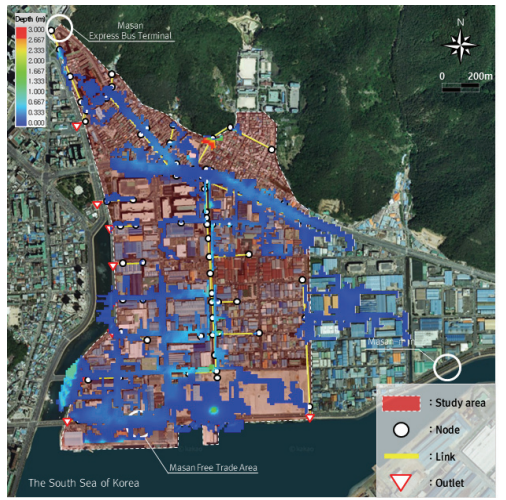

(d) 30-yr frequency condition

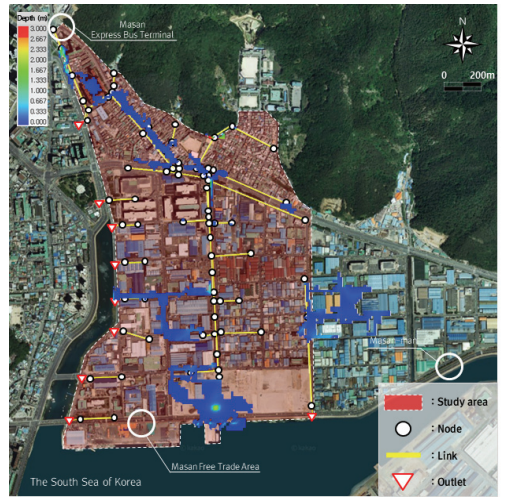

(b) A.H.H.W.L condition

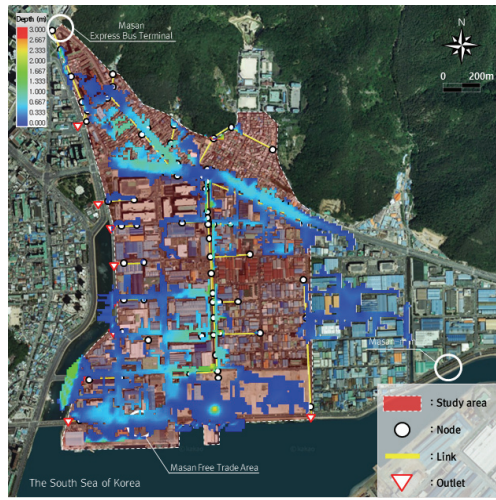

(e) 50-yr frequency condition

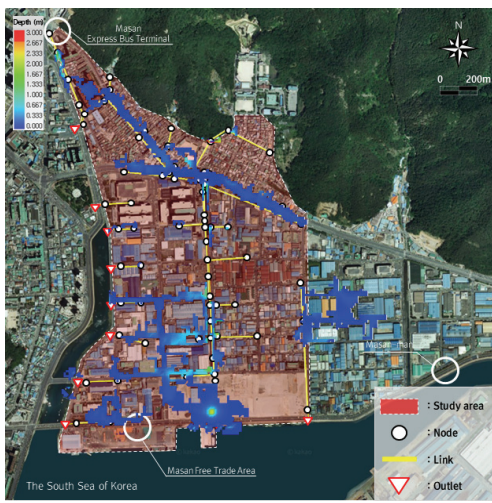

(c) $10-\mathrm{yr}$ frequency condition

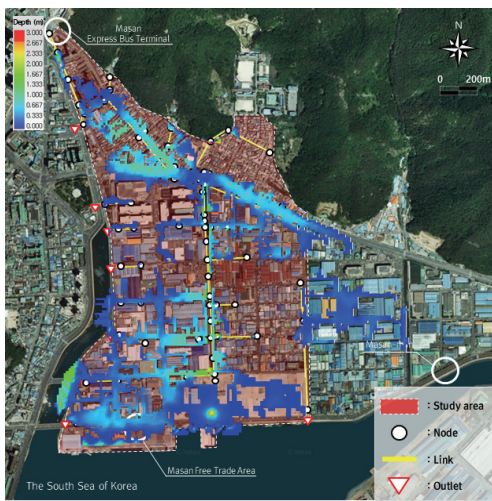

(f) 100-yr frequency condition

Fig. 4. Comparison of Flooding Results for Sea Level Conditions (Duration 3-hr) 


\section{4. 결 론}

최근 기존의 방재성능목표 이상의 초과강우사상이 빈번 히 발생하여 침수에 대한 위험도가 증가하고 있다. 이상기후 현상에 대비하고자 기후변화 시나리오에 따라 지역별 특성 에 따른 강우량의 변동을 면밀히 살펴볼 필요가 있다. 더불어 해수면 상승으로 인한 침수위험도를 함께 고려함으로써 연안도시 지역의 특성을 고려할 필요가 있다. 본 연구에서는 XP-SWMM 모형을 활용하여 경상남도 창원시 마산회원구 양덕 - 봉암동 일대에 향후 발생가능한 해수면 상승시나리 오를 고려한 분석을 진행하였다. 피해특성을 검토하는 방법 으로는 기 설정된 방재성능목표 강우량과 해수면 상승시나 리오를 조합하여 분석하였으며 침수범람도 작성에 따른 복합특성별 홍수 발생유형을 검토하였다. 분석 결과 해수면 의 상승을 고려하지 않은 경우보다 해수면의 상승을 고려한 경우 침수면적이 크게 증가한다는 결과를 확인하였다. 더불 어 특정 해수위 상승고 이상에서는 기 설정된 방재성능목표 강우량이 관리목표에 도달하지 못함을 확인하였다. 결국 지역별 방재성능목표는 기후변화와 도시화로 인해 침수피 해를 예방하기 위한 목표 강우량의 취지에 맞게 지역별 특성을 고려해야한다. 나아가 지역별 목표에 상응하는 배수 시스템의 개선이 함께 검토되어야 한다.

\section{감사의 글}

본 연구는 국토교통부/국토교통과학기술진흥원의 스마 트시티 혁신성장동력 프로젝트 지원으로 수행되었음(과제 번호 19NSPS-B154314-02).

\section{References}

Ahn, T.J. (2014). A study on applicability of the duration of target rainfall for achievement of regional disaster prevention performance. J. Korean Soc. Hazard Mitig., Vol. 14, No. 6, pp. 213-219.

Akter, T., Quevauviller, P., Eisenreich, S.J., and Vaes, G. (2018). Impacts of climate and land use changes on flood risk management for the Schijn River, Belgium. Environmental Science and Policy, Vol 89, pp. 163-175.

Cha, W.Y., Choi, J.H., Lee, O.J., and Kim, S.D. (2016). Probabilistic analysis of sea level rise in Korean major coastal regions under RCP 8.5 climate change scenario. J. Korean Soc. Hazard Mitig., Vol. 16, No. 6, pp. 389-396.

Cho, K., and Maeng, J.H. (2007). Some thoughts on direction to cope with the sea level rise in Korea.
Journal of the Korean Society for Marine Environmental Engineering, Vol. 10, No. 4, pp. 227-234.

Chu, H., Wei, J., Qiu, J., Li, Q., and Wang, G. (2019). Identification of the impact of climate change and human activities on rainfall-runoff relationship variation in the Three-River Headwaters region. Ecological Indicators, Vol. 106, 105516. doi:10.1016/j.ecolind.2019.105516

Cifrodelli, M., Corradini, C., Morbidelli, R., Saltalippi, C., and Flammini, A. (2015). The influence of climate change on heavy rainfalls in Central Italy. Procedia Earth and Planetary Science, Vol. 15, pp. 694-701.

Fadhel, S., Rico-Ramirez, M.A., and Han, D. (2018). Sensitivity of peak flow to the change of rainfall temporal pattern due to warmer climate. Journal of Hydrology, Vol. 560, pp. 546-559.

Hong, S.K., Kang, Y.H., and Lee, H.S (2013). A study on flooding prevention scheme due to sea level rise at Young-do coast in Busan. Journal of Navigation and Port Research, Vol. 37, No. 4, pp. 409-418.

Intergovernmental Panel on Climate Change (IPCC). (2014). Climate change 2014: Mitigation of Climate Change. Contribution of Working Group III to the Fifth Assessment Report of the Intergovernmental Panel on Climate Change. Cambridge, United Kingdom and New York, NY, USA: Cambridge Univ. Press.

Jeong, M.S., Oak, Y.S., Lee, Y.K., Lee, Y.S., Park, M.R., and Lee, C.H. (2017). Estimation of disaster prevention target rainfall according to urban disaster prevention performance. Journal of the Korea Academia-Industrial cooperation Society, Vol. 18, No. 4, pp. 101-110.

Jones, D.K., Zou, Q., and Reeve, D.E. (2013). Computational modelling of coastal flooding caused by combined surge overflow and wave overtopping on embankments. Journal of Flood Risk Management, Vol. 6, No. 2, pp. 70-84.

Joo, Y.M. (2015). Effects of sea level rise on the Mokpo coastal zone. Master's thesis, Mokpo National University, Korea.

Kim, J.S. (2016). Analysis of inundation causes in urban area based on application of prevention performance objectives. Journal of Wetlands Research, Vol. 18, 
No. 1, pp. 16-23.

Kim, M.S., Yoon, H.S., and Kim, K.H. (2019). A comparative study of long-term sea-level changes along the Busan coast due to climate change. Journal of Fisheries and Marine Science Education, Vol. 31, No. 1, pp. 83-93.

Ko, J.S., Ryu, G.H., and Jang, J.K. (2018). A study on improvement of target setting criteria for disaster prevention performance in Jeju Island, $J$. Korean Soc. Hazard Mitig., Vol. 18, No. 3, pp. 373-380.

Lee, N.E., Heo, J.R., Kal, B.S., and Park, J.B. (2016).

A study on establishment method of prevention capacity target against disasters considering sea level rise. J. Korean Soc. Hazard Mitig., Vol. 16, No.

2, pp. 523-527.

Ministry of the Interior and Safety (MOIS). (2017). Establishment of disaster prevention performance targets by region considering future climate change set and operating standards.

United Nations (UN). (2014). World urbanization prospects. Department of Economic and Social Affairs, United Nation, New York.
Park, Y.K., Kim, S.D., Lee, J.H., and Song, Y.H. (2018). Relationship analysis of sea level-rainfall for determination of disaster prevention performance in coastal cities. J. Korean Soc. Hazard Mitig., Vol. 18, No. 7, pp. 469-474.

Roberts, K.J., Colle, B.A., and Korfe, N. (2017). Impact of simulated twenty-first-century changes in extratropical cyclones on coastal flooding at the battery, New York City. Journal of Applied Meteorology and Climatology, Vol. 56, No. 2, pp. 415-432.

Verstraten, L., Wasko, C., Ashford, G., and Sharma, A. (2019). Sensitivity of Australian roof drainage structures to design rainfall variability and climatic change. Building and Environment, Vol. 161, 106230. doi:10.1016/j.buildenv.2019.106230

\begin{tabular}{l|l|} 
Received & October 22, 2019 \\
Revised & October 23, 2019 \\
Accepted & November 1, 2019
\end{tabular}

